\title{
HOME CARE OF THE SPINAL INJURY PATIENT
}

\author{
By A. Tricot, M.D., A. Heilporn, M.D., G. Dupire, Ph.T., M. Dernies, O.T.,
}

A. Devos and F. Monseux, S.W.

CTR-Hôpital Brugmann, Brussels, Belgium

OUR aim is to specify the conditions under which para- and tetraplegics may be successfully reintegrated into society. In particular we should like to devote our attention to a well-organised home-coming and to the therapy needed to maintain an initially satisfactory condition.

In the case of spinal lesions, the success of such reintegration consists in a function of:

I. Completion of a full functional rehabilitation programme.

2. Preparation of the family set-up.

3. Special adaptation of the home (when necessary).

The present study is limited to the main, vital elements in preparing the patient for discharge and to the care and treatment carried out at home.

\section{PREPARATION FOR GOING HOME}

This must be done at an early stage while the patient is still in the rehabilitation centre. The problems differ according to the severity of medullary lesions and are more complex in the case of cervical lesions. In any case the organisation and carrying out of this preparation and the subsequent planning of follow-up treatment are the result of the work of all members of the team. The problems are:

A. Personal Hygiene and Nursing. Once the specific nursing techniques have been established (skin care, micturition, evacuation, etc.), their efficiency is put to the test for they must not only be taught to the patient but to his immediate circle as well. This involves serious education with explanation of ways and means and observation of their practical application. The quality of the training can be tested during weekends at home before discharge. For tetraplegics, we particularly recommended a long period from two to four weeks at home before any final decision is made concerning discharge. This enables us to help realise with the family a practical application of the nursing and put it into practice: also to see how far the patient can become independent. We are thus able to note any improvements which can be brought to the programme and isolate any problems which remain to be solved.

The nursing staff maintain close contact with the family and are the permanent providers of practical information for the parents when they visit the centre. The other members of the team also provide information on each of the various aspects of re-education. Faced with a permanent disability and the new conditions that it implies, the family who has already been separated for several months is often distressed and worried. Here we emphasise the important part the Social Service 
plays by encouraging and helping individually, enabling the patient to become once again a well-balanced and well-adapted member of society.

This means that there must be frequent interviews with everyone concerned - using the methods of social case-work-both at the centre and at home.

B. Adapting the Home. The home must be adapted with a chairbound person in mind and the adaptations depend on the patient's degree of independence. Some of the problems which must be solved are common to all patients and others only arise in individual cases.

Our usual method is for the occupational therapist and the social worker to collaborate on the case-study. Such collaboration means that practical solutions and the necessary socio-economic support to put them into practice can be sought together. One or two visits to the home are needed, and it is usual for the patient to participate. Experience with the people going through our hands shows that there are certain problems of adaptation which occur very frequently.

The main problem met by the occupational therapist on home visits is the problem of access. The main difficulties for paraplegics are:

(i) steps at front or back;

(ii) upstairs bedrooms;

(iii) upstairs bathrooms and toilets (often small);

(iv) kitchens are impractical—cupboards too high, sinks difficult to get to;

(v) narrow doors.

Solutions are not always easy to find and depend on many different things, e.g. type of house or flat, whether accommodation is owner-occupied or rented and, most particularly, whether financial help is available. Solutions can be found in most cases, but if there are too many difficulties to be overcome we collaborate with the social worker and the family to find suitable accommodation elsewhere. In some cases it is only a question of giving practical advice and providing help.

These home visits are important both for the paraplegic and his family for, if the problem of access is solved, the paraplegic can become completely independent.

A large part of the costs of adapting the home can be paid from funds allocated according to somewhat strict criteria by a semi-governmental body, the Fonds National de Reclassement Social des Handicapés (National Fund for Reintegrating the Handicapped into Society). But the process is often a long one; payment of bills, which takes about a year, is conditional on the patient starting work. Apart from this financial aid towards adapting the home, there exists the possibility of applying to rent adapted accommodation from an organisation specialised in social accommodation. This type of adapted accommodation is still rare and the waiting list is exceptionally long. We are hoping that, in the future, five per cent of accommodation on each new social housing development will be adapted for the handicapped, the locomotor handicapped having priority. Finally, the world campaign of accessibility for the handicapped has been developing in Belgium for two years and the results so far obtained are encouraging.

C. Ambulation Training for the Paraplegics. This is undertaken when we feel there is sufficient likelihood of success. This therapy is given with the hope that once the activity is mastered, it will be used and maintained in the future. We should, however, point out that this is a somewhat precarious hope. A brief 
survey was in fact carried out at the end of I 973 on a control group of 46 paraplegic patients with a spinal lesion under Tro. All these subjects had left the service over a year before. Of the examples, I7 per cent had recovered sufficient use of their limbs to be able to do without a wheelchair; they walked either with the aid of a short double-bar leg-brace, or in some cases no brace at all. One, or a pair of sticks were needed although they were sometimes not necessary. Of the other 83 per cent using wheelchairs, 37 per cent had totally given up standing and 63 per cent still used their braces. This last group can be divided as follows: 64 per cent walk for an hour or more each day, 25 per cent for half an hour each day and I I per cent who only stand. We thus need to investigate in each individual case how we can prepare the subject to maintain these activities of ambulation and to encourage those around him to collaborate. Finally to judge the necessity of recommending follow-up therapy.

Our experience in physiotherapy leads us to point out the following:

(i) the necessity of informing the paraplegic's family of the possibilities of continuing walking exercises at home. This is particularly important for handicapped children;

(ii) the need to specify physiotherapy to be done at home in the face of the particular difficulties, set out below;

(iii) the great difficulty, under Belgian conditions, is finding a physiotherapist who is competent to undertake re-education and who is familiar with the specific problems of spinal lesions. This situation usually complicates the satisfactory organisation of home care.

D. Additional Problems concerning Tetraplegics. Preparing to go home involves other problems:

(i) the Social Service organises a nursing team, seeks the necessary financial support to pay for helpers and nurses and vital additional equipment such as an electrically-propelled wheelchair, a lifter etc.;

(ii) the physiotherapist establishes a necessary follow-up treatment which is considered vital in the case of cervical lesions. He also aims, as far as possible, to have a personal contact with the physiotherapist who will treat the patient at home;

(iii) the occupational therapist finds the materials and technical aids needed to give the patient maximum independence. He then ensures that the patient is sufficiently trained to use these aids and that family and helpers also know about them.

For the tetraplegic the same problems of accessibility are encountered, but in addition to this there is the question of adapted equipment. For the families of tetraplegics it is absolutely essential that they be equipped with the necessary individually adapted equipment, e.g. hoists, transfer boards and mobile arm supports.

The family must be properly informed about this equipment and also of the tetraplegic's own possibilities. Everything must be prepared to enable the tetraplegic to continue to do the maximum himself.

His activities are already very limited and this is therefore of first importance. Activities such as turning on the light or the radio, using the telephone, smoking 
reading, eating, brushing hair and teeth, shaving and making-up are things that the tetraplegic is often capable of doing alone or with the help of an orthesis, provided everything is at hand. The family must be told of this to reduce unnecessary work.

In our occupational therapy department, we have made a small electric box containing several sockets so that different electrical appliances (radio, lights, etc.) can be plugged in at the same time. This box is then placed so that the tetraplegic can switch on and off whichever appliance he wants without unnecessary effort. The cost is very low, which is an advantage.

The maximum must also be done to render the tetraplegic independent when in his wheelchair-if necessary, hand rims must be adapted and in some cases an electrically-propelled chair recommended. Here again the family must be informed and taught elementary manipulation of the chair in and out of doors and getting in and out of the car. This is particularly important if home care is to be properly carried out.

\section{DISCHARGE}

When the patient is discharged from the re-education centre:

(i) we ensure that the patient and his family have assimilated and understood the advice and recommendations given to them;

(ii) we check the efficacy of the organisation of the way of life at home as it has gradually been planned for him;

(iii) the doctor must complete the practical work by sending a report to the general practitioner and forwarding precise and detailed instructions to any nurse or physiotherapist who will be treating the patient at home.

\section{AFTER DISCHARGE, TRUE HOME CARE BEGINS}

A. We ensure that periodical medical check-ups are carried out. The patient comes to see us one month after his final discharge and after that we recommend our patients to come twice a year for control tests.

B. Nursing treatment at home is usually only prescribed for tetraplegics. The serious nature of the handicap means that the family must have help with personal and intimate care. The very high risk of bed sores etc. makes rigorous and regular preventive measures necessary. tives:

C. Follow-up physiotherapy is restricted to certain precisely defined objec-

(i) maintaining ambulation or even just standing exercises, when in view of the severity of the lesion, this ability is not guaranteed to continue, being at the limit to be able to realise it independently. In cases of severe and distressing spasticity of doubtful personal dynamism, of an insufficiently stimulating family set-up and this often due to over-protectiveness and when the patient is too old or too young.

In this particular field, the physiotherapist must be given precise details of the techniques used with the patient and be informed of his endurance; 
(ii) mobilisation to keep joint mobility and maintain functional positions in severe cases of spasticity;

(iii) systematically for the tetraplegic, to help him perserve the independence he has acquired and also as a preventive measure considering the many risks, physiotherapy includes joint mobilisation, breathing exercises, active mobilisation of muscle groups still innervated for voluntary movement. Regular treatment of this kind also has the advantage of keeping a check on the patient's general condition.

In all these particular cases, representing problematical situations, regular sessions with the therapist provide support for the patient and his family, giving the occasion in the case of problems to encourage a dynamic attitude and, above all, creating a reassuring link with the re-education team.

D. In Belgium, occupational therapy for homebound patients is not as well developed as one would like. It does not lie within the means of our centre to allow occupational therapists to work frequently outside the hospital. The result being that our action is therefore limited, especially in the case of spinal lesions. It is not always possible to foresee all the problems that may arise when preparing home and family for the discharge of the tetraplegic. Ideally, the occupational therapist should have time to do follow-up work. This means making a weekly visit after discharge to help the patient and family, and, more especially, adapting equipment to increase independence.

E. The Social Service, for its part, remains a constant support long after the patient has returned home. Returning home, the patient is confronted with many problems and the Social Service helps not only administratively but helps the patient and the family with their inter-relational problems. Although certain laws hinder people who go back to work, we encourage a return to professional activity but this is often acceptable only after all aspects of the administrative and economic situation have been dealt with and when the patient has been re-established in a balanced family environment. Thus the chances of success in this domain depend on maintaining regular contact after discharge. Particularly, in the case of tetraplegics, returning home is always very precarious with many risks of complications; it imposes a financial burden for the fit members of the family and in view of the many problems involved is very often difficult to organise. From the strictly medical point of view, it is hard to cater at home for all the needs of follow-up treatment. Ideally, the best solution would be to find accommodation for the tetraplegic-or, even better, for his family also-in a special institution. Apart from rare exceptions, our country is lacking in any institution of this kind. Placing a patient in an establishment is difficult to accept, is psychologically unsound and is often unsatisfactory from the point of view of medical techniques.

Thus, the only way out is often placing the patient in a hospital institution and such institutions are averse because they are overcrowded. One can imagine how the handicapped person must feel when faced with the prospect of spending his life in a hospital. Thus the choice-going home or going into an institution-is the outcome of a concerted decision between the patient and those around him. The alternative must be a genuine one, without uncertainty or doubt, allowing the patient to safeguard any remaining autonomy, however slight.

We consider it entirely justifiable to group together the very seriously handicapped in this case. This would allow organisation of the necessary services, 
provide greater security and make living conditions easier. This segregation has therefore many compensations. There is an urgent need for a well-thought-out plan for setting up such specialised institutions.

\section{CONCLUSIONS}

Home care must be carefully prepared while the patient is in the re-education centre.

As a general rule, the paraplegic is able to perform unaided the nursing duties and supervision which his handicap requires. This independence is the result of training which must be shared by those close relations with whom the patient lives. A proper understanding of what is required and correct execution of specific techniques are checked progressively during occasional weekends and leave at home. The therapeutic value of such leave should be emphasised.

Regular home therapy for these patients should be limited to:

(i) maintaining the ability to ambulate when the patient seems likely to regress, due to age, neurological symptoms or for psychological reasons;

(ii) preventing any complications arising from excessive spasticity.

The slowness of administrative procedures and the complexity of the economic situation often means that the patient comes under social care for several months after discharge.

In the case of tetraplegics, the organisation of permanent treatment includes:

(i) the organisation of a timetable to ensure that a capable helper is always present;

(ii) conscientious daily nursing;

(iii) follow-up physiotherapy whose functional and general preventive importance goes far beyond the simple performing of a therapeutic act;

(iv) we must point out the lack in our country of home occupational therapy, also the shortage of properly equipped dynamic centres for the severely handicapped and their families. We hope gradually to see these needs satisfied. 